7-1-2015

\title{
Median Nerve Mobility Measurement using a Motion Tracking Analysis Program: A Reliability Study
}

Consuelo Gonzalez-Suarez

University of Santo Tomas, bebetsuarez61@gmail.com

Jan Nathleen Dizon

University of Santo Tomas

Belinda Cabungcal-Fidel

University of Santo Tomas

Ronald Christopher A. Cua

University of Santo Tomas

Valentine C. Dones

University of Santo Tomas

See next page for additional authors

Follow this and additional works at: https://nsuworks.nova.edu/ijahsp

Part of the Occupational Therapy Commons, and the Other Rehabilitation and Therapy Commons

\section{Recommended Citation}

Gonzalez-Suarez C, Dizon JN, Cabungcal-Fidel B, Cua RC, Dones VC, Lesniewski P, et al. Median Nerve Mobility Measurement using a Motion Tracking Analysis Program: A Reliability Study. The Internet Journal of Allied Health Sciences and Practice. 2015 Jul 01;13(3), Article 4.

This Manuscript is brought to you for free and open access by the College of Health Care Sciences at NSUWorks. It has been accepted for inclusion in Internet Journal of Allied Health Sciences and Practice by an authorized editor of NSUWorks. For more information, please contact nsuworks@nova.edu. 


\title{
Median Nerve Mobility Measurement using a Motion Tracking Analysis Program: A Reliability Study
}

\author{
Abstract \\ Objective: To evaluate relative and absolute reliability and repeatability in assessing median nerve mobility \\ at the level of the wrist and distal upper arm of the right upper extremity during wrist extension. Methods: \\ Six healthy participants participated in the study. Median nerve mobility was captured three times at both \\ sites using Sonocyte Turbo by two sonologists for a total of 72 video clips (36 for each site and 18 by each \\ sonologist). Longitudinal movement was measured using Motion Tracking Analysis Program (MTAP) by \\ the two assessors who were rehabilitation medicine residents. After one month, the assessors remeasured \\ the longitudinal excursion of the median nerve of the previous video clips. Results: There was moderate \\ agreement between the two sonologists of the median nerve mobility at the level of the distal upper arm \\ and the wrist respectively. There was a moderate to almost perfect agreement between the two assessors' \\ readings in the mobility of the nerve at level of the distal upper arm and wrist for the first and second \\ readings. Repeatability testing showed that there was variable agreement at the level of the distal upper \\ arm and at the wrist. Conclusion: MTAP using fast template tracking with an adaptive template is a reliable \\ tool that can be employed in the accurate assessment of median nerve mobility at the distal upper arm \\ and wrist.

\section{Authors} \\ Consuelo Gonzalez-Suarez, Jan Nathleen Dizon, Belinda Cabungcal-Fidel, Ronald Christopher A. Cua, \\ Valentine C. Dones, Peter Lesniewski, and John C. Thomas
}




\title{
1IVAHSP \\ The Internet Joumnal of Allied Health Sciences and Practice \\ Dedicated to allied health professional practice and education \\ http://ijahsp.nova.edu Vol. 13 No. 3 ISSN 1540-580X
}

\section{Median Nerve Mobility Measurement using a Motion Tracking Analysis Program: A Reliability Study}

\author{
Consuelo Gonzalez-Suarez, MD, $\mathrm{PhD}^{1,2}$ \\ Jan Nathleen Dizon, MD2 \\ Belinda Cabungcal-Fidel, MD² \\ Ronald Christopher A. Cua, MD² \\ Valentin C. Dones, $\mathrm{PhD}^{1}$ \\ Peter Lesniewski, $\mathrm{PhD}^{3}$ \\ John C. Thomas, $\mathrm{PhD}^{4,5}$
}

1. Centre for Health Research and Movement Science, University of Santo Tomas, Manila, Philippines

2. Department of Physical Medicine and Rehabilitation, University of Santo Tomas Hospital, Manila, Philippines

3. School of Engineering, University of South Australia, Adelaide, South Australia

4. Group Scientific Pty Ltd, PO Box 190, Salisbury South, SA 5106, Australia

5. School of Electrical and Electronic Engineering, Shandong University of Technology, Zibo, China

Philippines/Australia/China

\begin{abstract}
Objective: To evaluate relative and absolute reliability and repeatability in assessing median nerve mobility at the level of the wrist and distal upper arm of the right upper extremity during wrist extension. Methods: Six healthy participants participated in the study. Median nerve mobility was captured three times at both sites using Sonocyte Turbo by two sonologists for a total of 72 video clips (36 for each site and 18 by each sonologist). Longitudinal movement was measured using Motion Tracking Analysis Program (MTAP) by the two assessors who were rehabilitation medicine residents. After one month, the assessors remeasured the longitudinal excursion of the median nerve of the previous video clips. Results: There was moderate agreement between the two sonologists of the median nerve mobility at the level of the distal upper arm and the wrist respectively. There was a moderate to almost perfect agreement between the two assessors' readings in the mobility of the nerve at level of the distal upper arm and wrist for the first and second readings. Repeatability testing showed that there was variable agreement at the level of the distal upper arm and at the wrist. Conclusion: MTAP using fast template tracking with an adaptive template is a reliable tool that can be employed in the accurate assessment of median nerve mobility at the distal upper arm and wrist.
\end{abstract}

\section{INTRODUCTION}

Carpal tunnel syndrome (CTS) is an entrapment of the median nerve as it passes under the flexor retinaculum at the wrist. ${ }^{1,2}$ The symptoms felt by patients with CTS are paresthesia and pain of the thumb, second, and third digits which are worse at night causing nocturnal awakening and relieved by flicking the hands. ${ }^{3}$ These symptoms may be either due to ischemia of the nerve, decrease in its longitudinal excursion, or its mechanical compression. ${ }^{4}$ There are various factors that are associated with its cause which could be either anatomic, systemic, occupational factors, or space occupying lesions. The precise etiology is unknown. ${ }^{5}$ Diabetes mellitus, pregnancy, thyroid disease, and obesity are conditions related with the development of CTS. ${ }^{6}$ Occupations involving high force and repetitive pressure with excessively flexed or extended wrist such as construction workers using jack hammer, clerical work, card dealers, and computer users predispose them to the development of CTS. ${ }^{6,7}$ It could also result from space occupying lesions such as tumors, osteophytes, and fracture callus.

It has been postulated that there is non-inflammatory fibrosis of the subsynovial connective tissue that alters the longitudinal and transverse motion of the median nerve and surrounding flexor tendons during hand movement, producing the symptoms of 


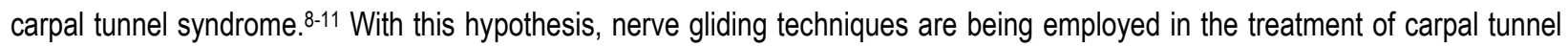
syndrome. These techniques attempt to place the nerve in tension and stretch it by appropriate mobilization through different postures, followed by applying slow, rhythmic movements directed towards the spinal cord and peripheral nerves. ${ }^{12}$ The structures that surround the nerve such as muscles and joints are likewise mobilized throughout the available range of motion. ${ }^{13-}$ $15 \mathrm{It}$ is postulated that they produce both mechanical and physiologic responses which will result in the regeneration and healing of the injured nerve..$^{15} \mathrm{~A}$ systematic review by McKeon and Yancosek showed that its effectiveness is not clear because of the relatively weak response of the participants. ${ }^{4}$ However, it has a trend towards the reduction of symptoms and improved sensation, function, and strength in addition to low monetary and temporal cost of treatment. ${ }^{4}$

Median nerve longitudinal movement has been analysed using high resolution, dynamic ultrasound either by frame-by-frame cross-correlation analysis of ultrasound images that measures the motion of fine speckle features in selected regions of interest of the median nerve, or by the spectral Doppler technique. ${ }^{16-18}$ Both absolute reliability determined using the standard error of the mean and minimal detectable change, and relative reliability determined using intraclass correlation have been reported. 19,20 Standard error of measurement (SEM) for speckle tracking and spectral Doppler was $0.31 \mathrm{~mm}$ and $0.66 \mathrm{~mm}$, respectively. ${ }^{16,21}$ Hough et al investigated median nerve mobility using spectral Doppler technique and showed excellent test-retest reliability with an intraclass correlation coefficient (ICC) of $0.92 .{ }^{16}$ However, the ultrasound image acquisition was performed by one sonologist and the images were analysed by a single operator. There is no study, to our knowledge, which assesses the reliability of different sonologists and operators in image acquisition and analysis.

Recently, a Motion Tracking Analysis Program (MTAP) using a fast template tracking method was developed and implemented in MatLab ${ }^{\text {TM }}$ by Nicoud et al at the Laser Light Scattering \& Materials Science Laboratory of the University of South Australia. 22,23 The method does fast template tracking using 2-dimensional (2D) normalized cross-correlation analysis and an adaptive template. The template being tracked is updated after each video frame and thus is successively adapted to improve tracking from frame-to-frame. The trajectory of a nerve is not usually a straight line along a particular geometric axis. Therefore, 2D crosscorrelation was used in order that the true $2 \mathrm{D}$ trajectory could be accurately retrieved. Furthermore, the nerve velocity is not constant throughout its motion, and determination of its instantaneous rather than average velocity is of interest. The instantaneous velocity calculated frame-by-frame.22,23 Fast template tracking may be used in the identification of the movement of organs, muscles, nerves, and layers of tissue. The current approach is limited to a 2-D motion. However, there is a growing interest in the use of 3 dimensional ultrasound in musculoskeletal ultrasound because it allows multiplanar reformats, and it provides a detailed imaging of superficial nerve bundles in relation to the anatomical landmarks. Progressing to 3-D will use the same principles of adaptive template matching by correlation. However the program currently used is limited to 2-D analysis, matching the current video format.

There has been no study testing the absolute and relative reliability of MTAP in assessing median nerve mobility. The purpose of this study is to evaluate relative reliability of MTAP by assessing the inter-rater reliability of two sonologists and assessors in measuring median nerve excursion at the level of the wrist and distal upper arm during wrist extension and to test the repeatability of measurements after one month. It also aims to determine the absolute reliability of the MTAP using standard error of measurement and minimal detectable change.

\section{MATERIALS AND METHODS}

The research was approved by the Ethics Committee of the College of Rehabilitation Sciences, University of Santo Tomas. Informed consent was obtained from the participants.

Setting: Department of Rehabilitation Medicine, Medicine Building, University of Santo Tomas

\section{Participants:}

Sample size calculation: Sample size calculation was performed based on the study Erel et al where the mean longitudinal excursion of the median nerve was $2.62 \mathrm{~mm}$ and standard deviation of $0.65 \mathrm{~mm} .{ }^{21}$ The minimum sample size is 5 using a power on 0.9 and significance level of 0.01 (Medcalc, version 11.0.1.0, MedCalc Software, Ostend, Belgium). ${ }^{23}$

Six healthy participants (two males and four females) with a mean age of $24 \pm 0.82$ years were included in the study. Volunteers were excluded if they had symptoms referring to the hand and neck, history of surgery to the neck and upper limbs, presence of peripheral neuropathy or cervical radiculopathy or a history of systemic disease associated with higher incidence of carpal tunnel syndrome such as diabetes mellitus, connective tissue diseases, thyroid disease or obesity.

(C) The Internet Journal of Allied Health Sciences and Practice, 2015 
Testers: The two sonologists were physiatrists who had been performing musculoskeletal ultrasound for six years while the two assessors were Rehabilitation Medicine residents. Prior to the study, the sonologists discussed the anatomical landmarks that were used in identifying the median nerve in the wrist and distal upper arm. For the wrist, the surface landmark used was the distal wrist crease which coincides with the proximal border of the flexor retinaculum, while the ultrasonographic landmark was the distal end of the radius. ${ }^{21}$ For the distal upper arm, the surface landmark was the elbow crease. Since there is no bony landmark that could be visualized in ultrasound, the median nerve was identified in cross section as it courses with the brachial artery. This area is located in the distal aspect of the upper arm above the level of the elbow crease.

The assessors were trained in using the Motion Tracking Analysis Program (MTAP). They decided on the feature of interest (FOI) of the median nerve at the level of distal upper arm and wrist. At the distal upper arm, the FOI was recorded 2-6 cm from the left lateral edge of the screen of the laptop computer because there was no visible bony landmark as a reference point. At the wrist, the feature of interest (FOI) was placed 2 to $5 \mathrm{~cm}$ proximal to the midpoint of the distal radius. The feature of interest was measured with a size of $0.3 \times 0.3 \mathrm{~cm}$, limiting the FOl only to the nerve fascicles and excluding the epineurium.

\section{Musculoskeletal (MSUS) Image Acquisition:}

A Sonocyte Turbo ultrasound instrument with a $38 \mathrm{~mm}$ linear array transducer with a10 $\mathrm{MHz}$ frequency was used. The resolution of the ultrasound image was $1280 \times 1024$ pixels and this was converted to an AVI video with a resolution of $320 \times 240$ pixels at 25 frames per second. The video was then converted to 8-bit grayscale (8 bits per pixel with 256 shades of gray). A 151 frame sequence was analysed.

The participants laid supine on a plinth with the right upper extremity resting on a specially designed frame which kept the shoulder at $90^{\circ}$ abduction, forearm fully supinated, with the elbow and the metacarpophalangeal and interphalangeal joints extended (Fig 1). The frame had a wrist and arm support which allowed extension of the wrist only up to $60^{\circ}$. The wrist was initially positioned in a neutral position and was passively extended to $60^{\circ}$ by the research assistant. The transducer was placed transversely on the ventral wrist. The median nerve was scanned in short axis using B mode (a 2-dimensional diagnostic ultrasound presentation of echo-producing interfaces in a single plane), as it was superficial to the flexor digitorum superficialis. It was tracked distally for about $4 \mathrm{~cm}$ to identify its course and anatomical relations. After obtaining a clear image, the depth was adjusted to $2.7 \mathrm{~cm}$ and the focus was set at the level of the median nerve. The transducer was positioned longitudinally and the wrist was extended repeatedly to assist in locating the median nerve.

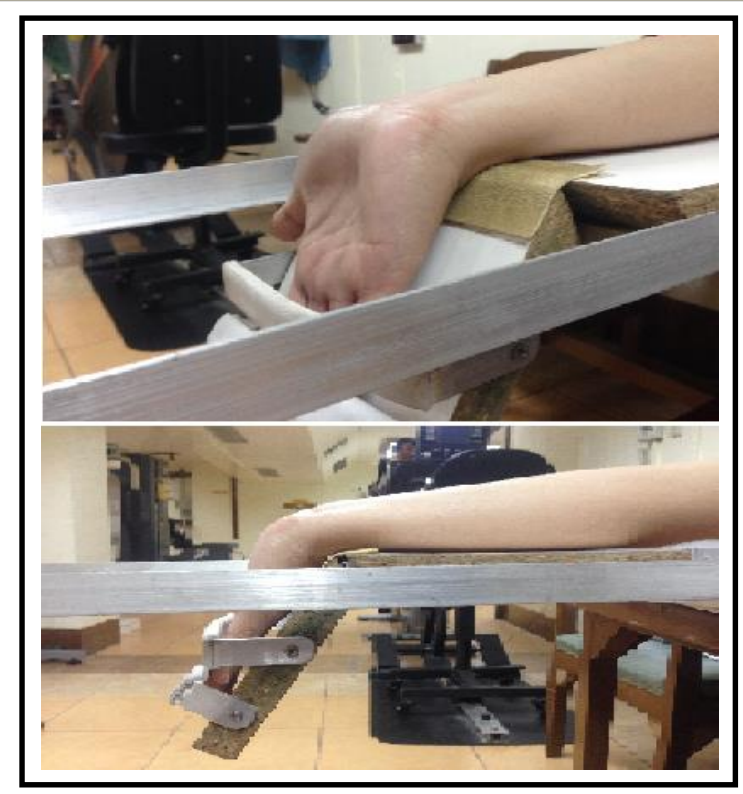

Figure 1: Frame used in the study limiting dorsiflexion of the wrist.

The test movement was passive extension of the wrist from neutral to $60^{\circ}$ while maintaining the metacarpophalangeal and interphalangeal joints of the thumb and fingers in extension. Movement was performed for 4 seconds using a timer and was recorded by continuous video acquisition (cine-loop) with a duration of 6 seconds. The procedure was repeated three times. 
The transducer was then placed transversely approximately $7 \mathrm{~cm}$ proximal to the elbow crease. The median nerve was identified in a transverse scan where it was medial to the brachial artery and was tracked proximally. ${ }^{24} \mathrm{An}$ area where movement of the transducer was minimal during the wrist extension was identified. This was important because transverse movement can cause the nerve to move out of plane when the nerve is scanned longitudinally. ${ }^{13}$ The transducer was placed longitudinally and was aligned along the course of the median nerve to capture the video image. Wrist extension was performed. This was repeated and recorded three times. Only the right upper extremity was used in the study. After the procedure, the participants rested in a sitting position for an hour before being positioned for the procedure that was performed by the second sonologist

\section{MSUS Image Analysis:}

A total of 72 recordings (18 each for the movement of the median nerve at the wrist and distal upper arm for each sonologist) were saved. The ultrasound images were exported as digital images into a laptop as uncompressed audio-video interleave (.avi, or "AVl" herein) files. The uncompressed AVIs were then imported into MATLAB (7.5, R2010b; The Math Works, Inc., Natick, Massachusetts) and analyzed with the MTAP application. Each video clip was analysed frame-by-frame. The feature of interest (FOI) in the nerve was identified and cropped in the first frame. This selected image became the initial template to be tracked. The template was cross-correlated with the second frame of the video and the region of best match generated the next version of the template which was tracked in the subsequent frame and so on until the last frame was processed. This adaptive template approach accommodates the small changes which occur in the feature being tracked over several frames and improves the tracking greatly. ${ }^{22,23}$

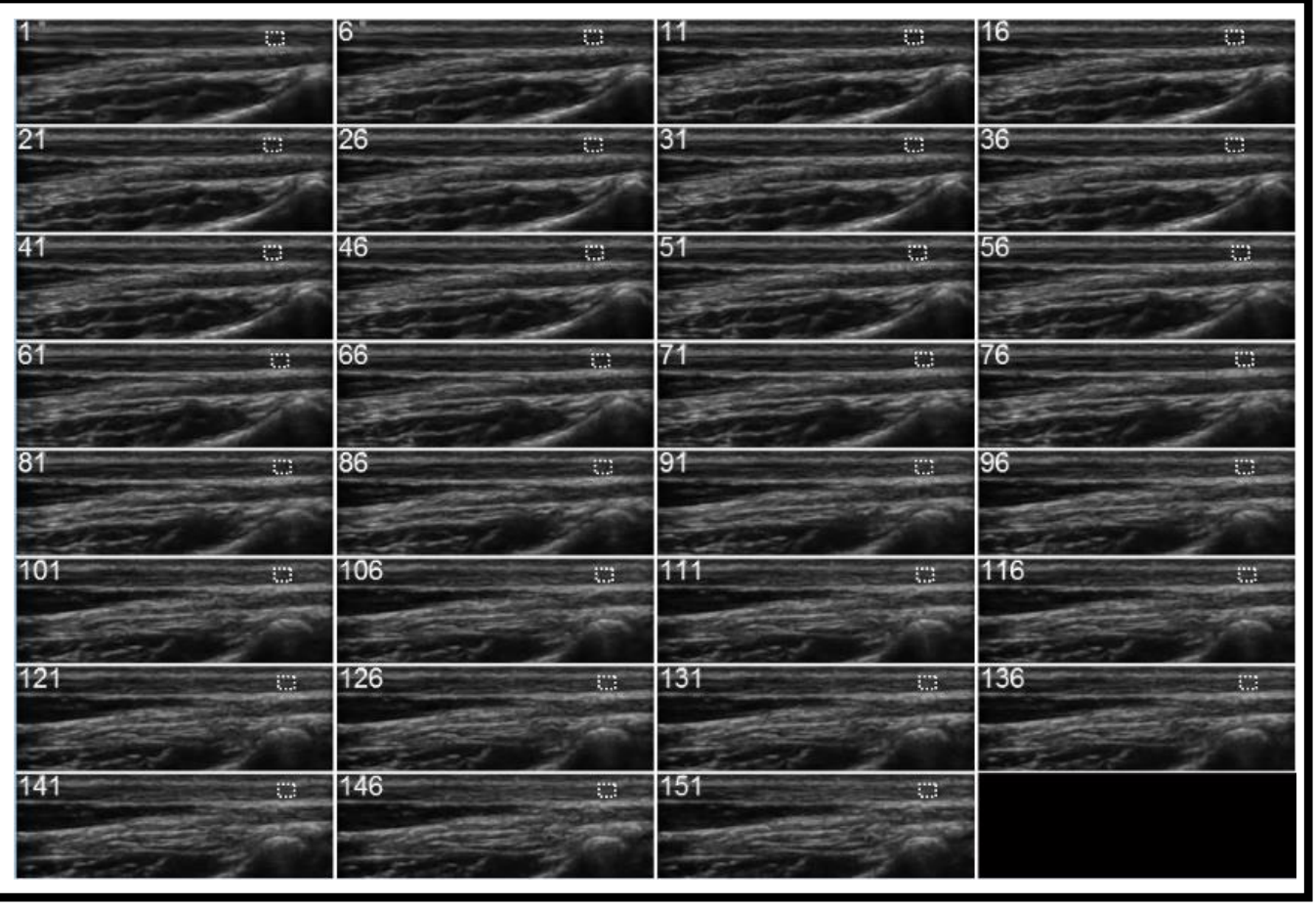

Figure 2: Fast template tracking of the median nerve at the level of the wrist. Every fifth frame is shown and the dotted rectangle is the feature of interest (template) being tracked. It can be seen that the feature is tracked reliably over the 151 frames and, looking vertically down through the frame sequence, the feature moves to the right. 


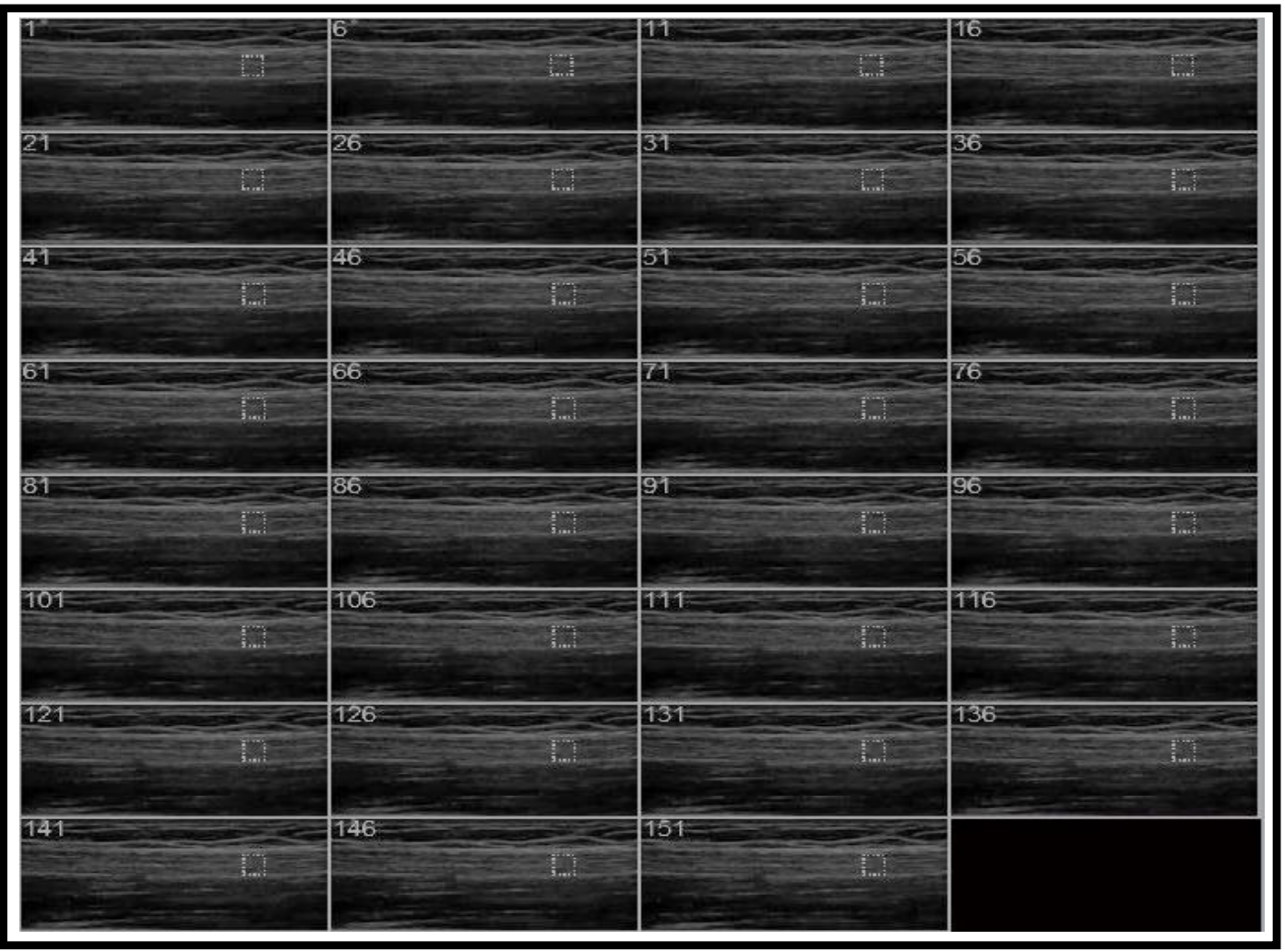

Figure 3: Fast template tracking of the median nerve at the level of the distal upper arm. Every fifth frame is shown and the dotted rectangle is the feature (template) being tracked. It can be seen that the feature is tracked reliably over the 151 frames and, looking vertically down through the frame sequence, the feature moves to the right.

The tracking trajectory generated by the MTAP application was exported to a Microsoft Excel (MSExcel) spreadsheet where the trajectory of the template having the $X$ and $Y$ coordinates was recorded each frame. The initial and final $X$ and $Y$ values were the initial and final pixel positions of the selected template within the video frames. The linear displacement in pixels between frames was readily calculated from the difference in $X$ and $Y$ pixel values between subsequent frames. The displacement in pixels was converted into millimetre where one millimetre was equal to 3.78 pixels.

The two assessors analysed the ultrasound imaging tracking results independently using the same computer with a one day interval. After one month, the measurements were repeated by the same assessors.

\section{STATISTICAL ANALYSIS}

The displacement data generated by the two assessors were entered in an MS Excel spreadsheet. MedCalc software (version 11.0.1.0, MedCalc Software, Ostend, Belgium) was used for the statistical analysis of the data from the assessors. The measurements of the displacement of the median nerve in the distal upper arm and wrist were characterized by determining the mean displacement, standard deviation, $95 \%$ confidence interval, and standard error of the measurements. The intra-class correlation coefficient test for absolute agreement with a two-way mixed model was used to determine the inter-rater reliability of the two sonologists. The measurements of the two assessors was analysed separately. The same statistical tools were used to determine inter-rater reliability of the two assessors and the repeatability of measurements of the assessors after one month. For the ICC, 0 to 0.2 was considered as having poor agreement, 0.3 to 0.4 as fair agreement, 0.5 to 0.6 as moderate agreement, 0.7 to 0.8 as strong agreement and $>0.8$ as almost perfect agreement. The pooled standard error of measurement (SEM) and minimal detectable change (MDC) were also calculated.

and $\quad M D C=1.96 \times \sqrt{2}$ SEM 


\section{RESULTS}

Inter-rater reliability of the sonologists and assessors

Tables 1 and 2 summarize the statistical analysis results and show the means, SEM and 95\% confidence intervals of the movement of the median nerve at the level of the distal upper arm and wrist. For both assessors, the ICC showed moderate agreement between the two sonologists of the median nerve mobility at the level of the distal upper arm specifically (Table 1 and 2):

Assessor 1: ICC: 0.63 (95\% Cl: 0.02, 0.86); Pooled SEM: 0.03mm; MDC: $0.07 \mathrm{~mm}$ and Assessor 2: ICC: 0.66 (95\% Cl: 0.14, 0.86); Pooled SEM: $0.02 \mathrm{~mm}$; MDC: $0.5 \mathrm{~mm}$

There is almost perfect agreement for the median nerve mobility at the level of the wrist, specifically:

Assessor 1: ICC: 0.92 (95\% Cl: 0.67, 0.97); Pooled SEM: $0.06 \mathrm{~mm}$; MDC: $0.16 \mathrm{~mm}$ and

Assessor 2: ICC: 0.92 (95\% Cl: 0.79, 0.97); Pooled SEM: $0.08 \mathrm{~mm}$; MDC: $0.23 \mathrm{~mm}$

Table 1: Inter-rater reliability of the two sonologists of median nerve mobility at the level of distal arm (millimiters)

\begin{tabular}{|c|c|c|c|c|}
\hline & $\begin{array}{c}\text { Mean } \pm \text { SD } \\
(95 \% \text { confidence } \\
\text { interval) }(\mathrm{mm}) \\
(\mathrm{N}=18)\end{array}$ & SEM & $\mathrm{MDC}(\mathrm{mm})$ & $\begin{array}{l}\text { Inter-rater reliability testing } \\
\text { ICC } \\
\text { Pooled SEM }(\mathrm{mm}) \\
\text { MDC }(\mathrm{mm})\end{array}$ \\
\hline \multicolumn{5}{|l|}{$\begin{array}{l}\text { Measured by } \\
\text { Assessor } 1\end{array}$} \\
\hline Sonologist 1 & $\begin{array}{c}0.32 \pm 0.06 \\
(95 \% \mathrm{Cl}: 0.29,0.35)\end{array}$ & 0.01 & 0.04 & \multirow{2}{*}{$\begin{array}{l}\text { ICC: } 0.63(0.02,0.86) \\
\text { Pooled SEM: } 0.03 \\
\text { MDC: } 0.07\end{array}$} \\
\hline Sonologist 2 & $\begin{array}{c}0.33 \pm 0.12 \\
(95 \% \mathrm{Cl} 0.28,0.40)\end{array}$ & 0.02 & 0.08 & \\
\hline \multicolumn{5}{|l|}{$\begin{array}{l}\text { Measured by } \\
\text { Assessor } 2\end{array}$} \\
\hline Sonologist 1 & $\begin{array}{c}0.31 \pm 0.04 \\
(95 \% \mathrm{Cl} 0.28,0.34)\end{array}$ & 0.01 & 0.03 & \multirow{2}{*}{$\begin{array}{l}\text { ICC: } 0.66(0.14,0.86) \\
\text { Pooled SEM: } 0.02 \\
\text { MDC: } 0.5\end{array}$} \\
\hline Sonologist 2 & $\begin{array}{c}0.36 \pm 0.03 \\
(95 \% \mathrm{Cl} 0.29,0.42)\end{array}$ & 0.13 & 0.09 & \\
\hline
\end{tabular}

ICC: intraclass correlation; SEM: standard error of measurement; MDC: minimal detectable change

Table 2: Inter-rater reliability of the two sonologists of median nerve mobility at the level of the wrist ICC: intraclass correlation; SEM: standard error of measurement; MDC: minimal detectable change

\begin{tabular}{|l|c|c|c|c|}
\hline & $\begin{array}{c}\text { Mean } \pm \text { SD } \\
(95 \% \text { confidence } \\
\text { interval }) \\
(\mathrm{mm}) \\
(\mathrm{N}=18)\end{array}$ & SEM & MDC $(\mathrm{mm})$ & $\begin{array}{c}\text { Inter-rater reliability testing } \\
\text { ICC } \\
\text { Pooled SEM }(\mathrm{mm}) \\
\text { MDC }(\mathrm{mm})\end{array}$ \\
\hline $\begin{array}{l}\text { Measured by } \\
\text { Assessor 1 }\end{array}$ & & & & \\
\hline Sonologist 1 & $\begin{array}{c}0.43 \pm 0.19 \\
(95 \% \mathrm{Cl}: 0.33,0.53)\end{array}$ & 0.04 & 0.12 & $\begin{array}{l}\text { ICC: } 0.92(0.67,0.97) \\
\text { Pooled SEM: } 0.06 \\
\text { MDC: } 0.16\end{array}$ \\
\hline Sonologist 2 & $\begin{array}{c}0.41 \pm 3.0 \\
(95 \% \mathrm{Cl}: 0.33,0.48)\end{array}$ & 0.14 & 0.09 & \\
\hline Measured by & & & & $\begin{array}{l}\text { ICC: } 0.92(0.79,0.97) \\
\text { Pooled SEM: } 0.08 \\
\text { Assessor 2 }\end{array}$ \\
\hline Sonologist 1 & $\begin{array}{c}0.42 \pm 0.24 \\
(95 \% \mathrm{Cl}: 0.31,0.54)\end{array}$ & 0.06 & 0.15 & MDC: 23 \\
\hline Sonologist 2 & $0.48 \pm 0.38$ & 0.09 & 0.25 & \\
\hline
\end{tabular}


Table 3 and 4 gives the statistical analysis results for both assessors for the first and second readings. There was almost perfect agreement between the two assessors' readings in the mobility of the nerve at level of the distal upper arm for both readings. For the initial reading, the assessors' ICC is $0.93(95 \% \mathrm{Cl}: 0.87,0.97)$; pooled SEM: $0.02 \mathrm{~mm}$ and MDC is $0.05 \mathrm{~mm}$ while for the second reading, the ICC is 0.91 ( $95 \% \mathrm{Cl}: 0.82,0.95)$; pooled SEM of $0.03 \mathrm{~mm}$ and MDC of $0.09 \mathrm{~mm}$.

The results obtained for both assessors for median nerve mobility at the level of the wrist showed a perfect correlation for the initial reading with an ICC of $0.82(95 \% \mathrm{Cl}: 0.66,0.91)$ with a pooled SEM of $0.3 \mathrm{~mm}$ and MDC of $0.82 \mathrm{~mm}$ pixels. For the second reading, the correlation was moderate with an ICC is 0.68 ( $95 \% \mathrm{Cl}: 0.37,0.83$ ) and a pooled SEM of $0.31 \mathrm{~mm}$ and MDC of $0.86 \mathrm{~mm}$. Repeatability testing showed that there was poor agreement between both readings of Assessors 1 and 2 at the level of the distal upper arm (Assessor 1: ICC 0.21 [95\% Cl: -0.55, 0.59] and Assessor 2: ICC 0.03 [95\% Cl: -0.95, 0.51]), respectively, while there was moderate and strong agreement of the reading of Assessor 1 and 2, respectively, at the level of the wrist (Assessor 1 ICC: 0.64 [95\% Cl: 0.30,0.82] and Assessor 2 ICC: 0.78 [95\% Cl: 0.58, 0.89]).

\section{Absolute Reliability (Pooled SEM and Minimum detectable change):}

As can be seen from Table 1 and 2, the pooled SEM for median nerve mobility at the distal upper arm by Assessor 1 and 2 was 0.03 and $0.02 \mathrm{~mm}$ while the MDC was 0.07 and $0.5 \mathrm{~mm}$ respectively. At the level of the wrist, the pooled SEM was 0.06 and 0.08 $\mathrm{mm}$ for Assessor 1 and 2 while the MDC was 0.16 and $0.23 \mathrm{~mm}$ respectively.

Table 3 and 4 show the pooled SEM and MDC of the assessors during the first and second readings. For the initial reading, the pooled SEM at the level of distal upper arm and wrist was 0.02 and $0.3 \mathrm{~mm}$ while the MDC was 0.05 and $0.3 \mathrm{~mm}$ respectively. For the second reading, the pooled SEM at the distal upper arm and wrist was 0.03 and $0.31 \mathrm{~mm}$ pixels while the MDC was 0.09 and $0.86 \mathrm{~mm}$.

Table 3: Inter-rater reliability and repeatability of the two assessors of median nerve mobility at the level of distal upper

\begin{tabular}{|c|c|c|c|c|c|c|}
\hline \multicolumn{7}{|c|}{ arm } \\
\hline & \multicolumn{2}{|c|}{ First Reading } & \multicolumn{2}{|c|}{ Second Reading } & \multirow[b]{2}{*}{$\begin{array}{c}\mathrm{P} \\
\text { value }\end{array}$} & \multirow[b]{2}{*}{$\begin{array}{l}\text { Repeatabilityl } \\
\text { CC(95\% Cl) }\end{array}$} \\
\hline & $\begin{array}{c}\text { Mean } \pm \text { SD } \\
(95 \% \mathrm{Cl}) \\
(\mathrm{mm}) \\
(\mathrm{N}=36)\end{array}$ & $\begin{array}{l}\text { SEM } \\
(\mathrm{mm})\end{array}$ & $\begin{array}{c}\text { Mean } \pm \text { SD } \\
(95 \% \mathrm{Cl}) \\
(\mathrm{mm}) \\
(\mathrm{N}=36)\end{array}$ & $\begin{array}{l}\text { SEM } \\
(\mathrm{mm})\end{array}$ & & \\
\hline Assessor 1 & $\begin{array}{l}0.36 \pm 0.09 \\
(0.32,0.39)\end{array}$ & 0.01 & $\begin{array}{r}0.33 \pm 0.10 \\
0.30,0.36)\end{array}$ & 0.02 & NS & $\begin{array}{c}0.21 \\
(0.51,0.59)\end{array}$ \\
\hline Assessor 2 & $\begin{array}{l}0.33 \pm 0.07 \\
(0.30,0.35)\end{array}$ & 0.01 & $\begin{array}{c}0.34 \pm 0.1 \\
(95 \% \text { Cl: } 0.30,0.37)\end{array}$ & 0.03 & NS & $\begin{array}{c}0.03 \\
(-0.95,0.51)\end{array}$ \\
\hline $\begin{array}{l}\text { Inter-rater reliability } \\
\text { ICC }(95 \% \mathrm{Cl}) \\
\text { Pooled SEM (mm) } \\
\text { MDC (mm) }\end{array}$ & \multicolumn{2}{|c|}{$\begin{array}{c}0.93(0.87,0.97) \\
0.02 \\
0.05\end{array}$} & \multicolumn{2}{|c|}{$\begin{array}{c}0.91(0.82,0.95) \\
0.03 \\
0.09\end{array}$} & & \\
\hline
\end{tabular}

ICC: intraclass correlation; SEM: standard error of measurement; MDC: minimal detectable change; NS: not significant 
Table 4: Inter-rater reliability and repeatability of the two assessors of median nerve mobility at the level of wrist

\begin{tabular}{|c|c|c|c|c|c|c|}
\hline & \multicolumn{2}{|c|}{ First Reading } & \multicolumn{2}{|c|}{ Second Reading } & \multirow[b]{2}{*}{$\begin{array}{c}P \\
\text { value }\end{array}$} & \multirow[b]{2}{*}{$\begin{array}{l}\text { Repeatability } \\
\text { ICC }(95 \% \mathrm{Cl})\end{array}$} \\
\hline & $\begin{array}{c}\text { Mean } \pm \text { SD } \\
(95 \% \mathrm{Cl}) \\
(\mathrm{mm}) \\
(\mathrm{N}=36)\end{array}$ & $\begin{array}{l}\text { SEM } \\
(\mathrm{mm})\end{array}$ & $\begin{array}{c}\text { Mean } \pm \text { SD } \\
(95 \% \mathrm{Cl}) \\
(\mathrm{mm}) \\
(\mathrm{N}=36)\end{array}$ & $\begin{array}{l}\text { SEM } \\
(\mathrm{mm})\end{array}$ & & \\
\hline Wrist Assessor 1 & $\begin{array}{c}0.44 \pm 0.22 \\
(0.36,0.51)\end{array}$ & 0.04 & $\begin{array}{l}0.42 \pm 0.16 \\
(0.360 .47)\end{array}$ & 0.02 & NS & $\begin{array}{c}0.64 \\
(0.30,0.82)\end{array}$ \\
\hline Wrist Assessor 2 & $\begin{array}{c}0.45 \pm 0.31 \\
(0.35,0.56)\end{array}$ & 0.5 & $\begin{array}{c}0.45 \pm 0.31 \\
(0.34,0.55)\end{array}$ & 0.05 & NS & $\begin{array}{c}0.78 \\
(0.58,0.89)\end{array}$ \\
\hline $\begin{array}{l}\text { Inter-rater reliability } \\
\text { ICC }(95 \% \mathrm{Cl}) \\
\text { Pooled SEM (mm) } \\
\text { MDC (mm) }\end{array}$ & \multicolumn{2}{|c|}{$\begin{array}{c}0.82(0.66,0.91) \\
0.3 \\
0.82\end{array}$} & \multicolumn{2}{|c|}{$\begin{array}{c}0.68(0.37,0.83) \\
0.31 \\
0.86\end{array}$} & & \\
\hline
\end{tabular}

ICC: intraclass correlation; SEM: standard error of measurement; MDC: minimal detectable change; NS: not significant

\section{DISCUSSION}

Our study used a fast template tracking method which is similar to the one designed by Erel et al. ${ }^{21}$ They fitted a quadratic equation to the three correlation coefficients closest to the maximum to determine the position of the best template match in the frame, effectively interpolating the maximum location in the correlation matrix. In our case, utilizing an adaptive template, which is updated after each frame and correlation, allowed us to use a single correlation matrix maximum to determine the position of the best template fit in each frame. We also displayed the dynamic correlation matrix as a surface plot to monitor and verify that the maxima are well defined and are single in each matrix. Figure 4 gives an example of a template trajectory and velocity while Figure 5 shows a typical correlation matrix surface plot with a well-defined, single maximum.

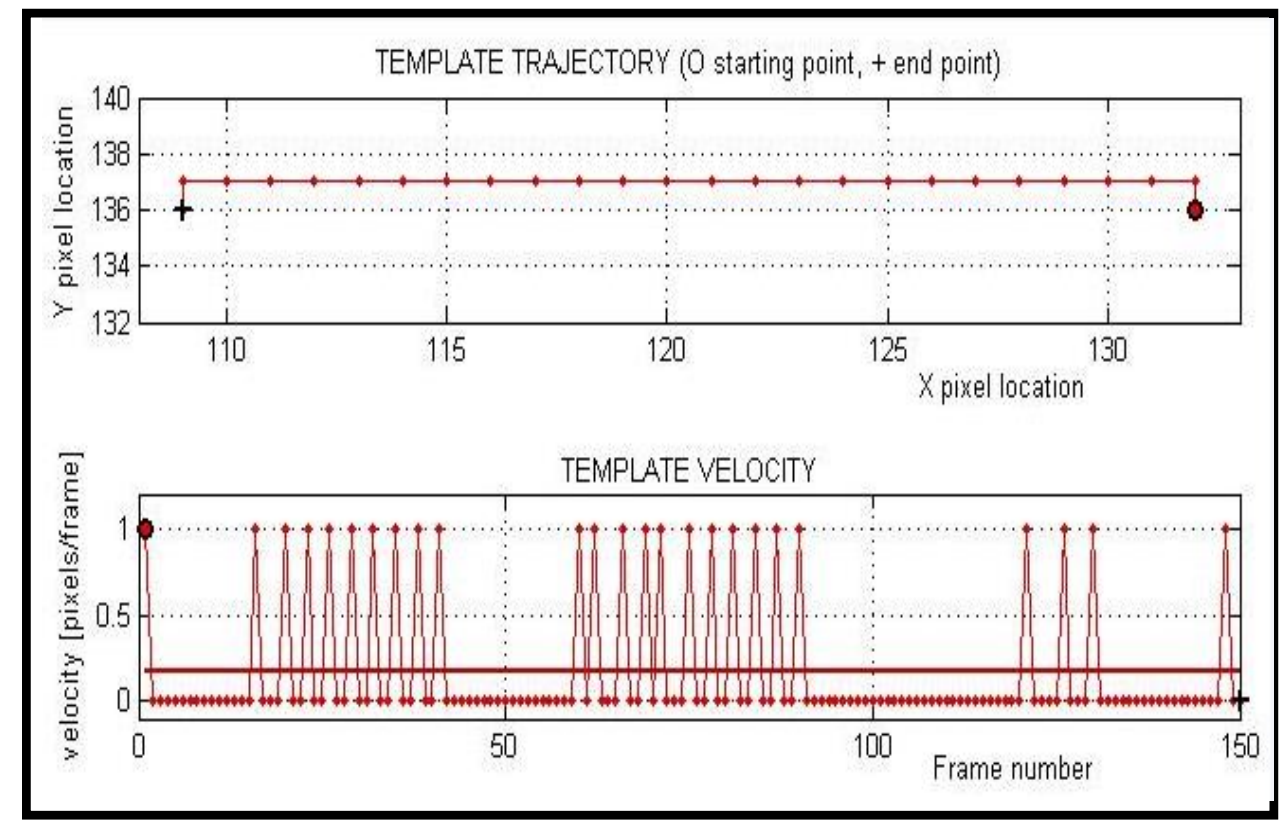

Figure 4. Template Trajectory and Speed (informally labelled "Velocity" in the plot) of a $15 \times 41$ pixel feature in a part of a video of the wrist. Note: registered dominant horizontal $(x)$ displacement of 23 pixels in 151 frames with low velocity not exceeding one pixel per frame (in the velocity plot - average value is shown as a darker continuous trace). 


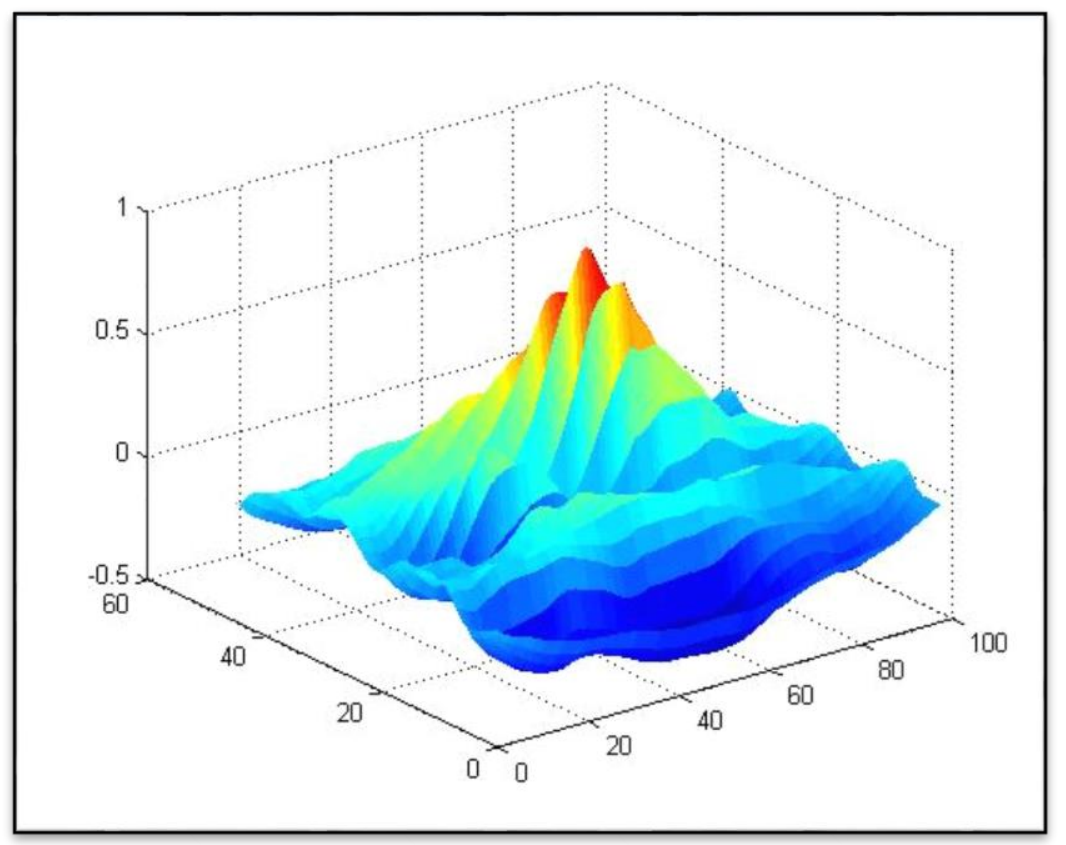

Figure 5. Normalized two-dimensional cross-correlation output (z-axis). The vertical, z-axis shows the normalized correlation values, which represents the match between the 2-dimensional templates for each of its shift in pixels around the last position (i.e. pixel offset as shown in $x, y$ - axes). Location of the maximum value/highest point of this plot identifies the next location of the current template in terms of the $x$, y pixels shift (frame No 5, example as in Figure 3 ).

Note that although the dominant template motion was in the horizontal $(x)$ direction from right to left, there was also minute vertical (y) motion in the first and near the last frame of the analysis, which was represented as single spikes of speed in the initial and near the last frame. As can be seen, limited resolution of the video imposes an error of one pixel per frame on the velocity and trajectory.

Our study showed moderate intra-class correlation between the two sonologists in measuring the mobility of the median nerve at the level of the distal upper arm and almost perfect agreement between the readings at the level of the wrist. The better agreement between the sonologists for the measurements at the level of the wrist may be secondary to the seemingly tight anatomical relationship of the median nerve with its surrounding structures in the wrist. At the level of the wrist, the median nerve is surrounded by the flexor retinaculum, tendons of the flexor digitorum superficialis and flexor digitorum profundus. ${ }^{25}$ This potentially prevents the median nerve from bowing. Conversely, at the level of the distal upper arm, the median nerve appears to be more mobile compared with mobility at the level of the wrist as it courses in the groove between the biceps brachii and brachialis muscles. Bilecoenoglu et al suggested that the median nerve in this area is not likely to be compressed. ${ }^{26}$ Considering the anatomical arrangement of the median nerve at the level of the distal upper arm and its low probability of being compressed, we hypothesise that there could be considerable bowing of the median nerve as seen in the ultrasound images in Fig. 6 . 


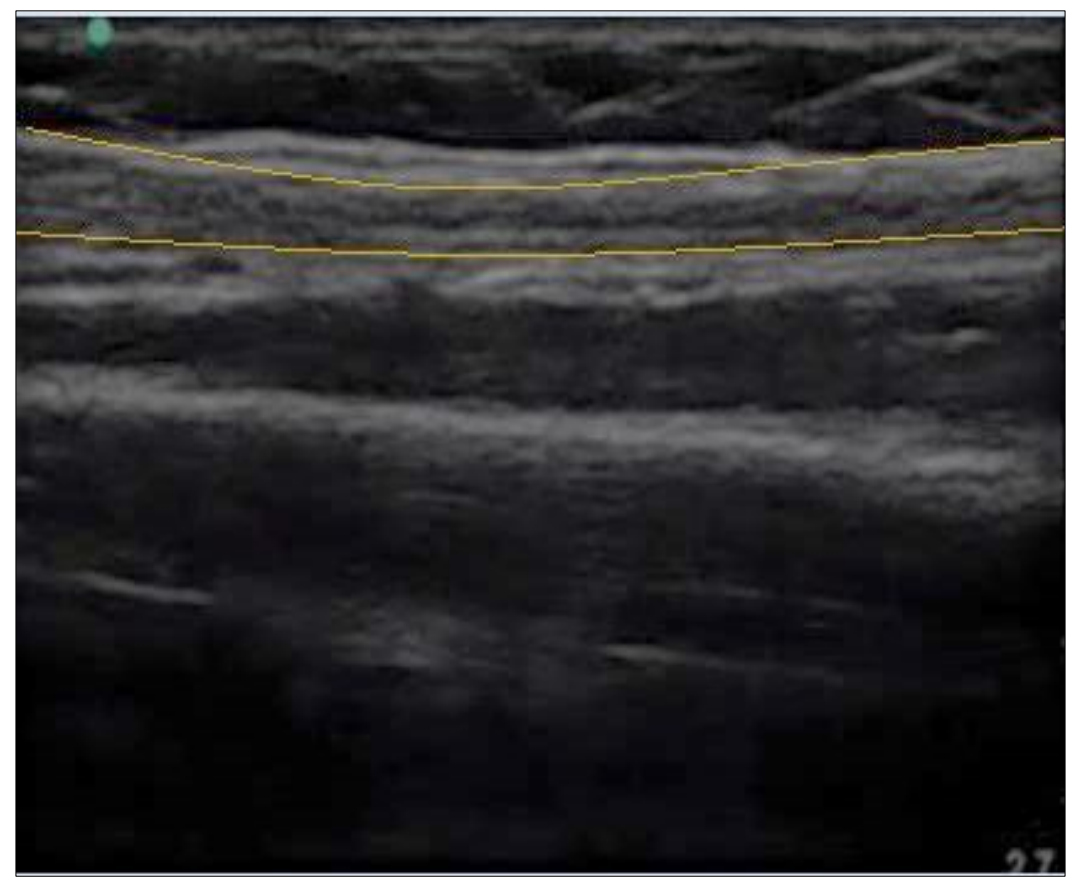

Figure 6. Median nerve at the level of the distal upper arm. Bowing of the median nerve is evident. (Median nerve is outlined with yellow line.)

One of the difficulties in tracking nerve mobility using MSUS images is inadequate definition of the feature of interest of the nerve due to changes in the shape and orientation of the nerve in each of the frames. ${ }^{22,23}$ We observed that the median nerve has a tendency to arch at the level of the distal upper arm causing deformation of the median nerve as seen in Fig 6 . In addition, there is low contrast and low signal-to-noise ratio in the MSUS images of the median nerve which adds to the difficulty in imaging it.22,23 This underpins the importance of the pilot test in determining the proper placement of the MSUS transducer head, which was conducted prior to the implementation of our study. Current studies assessing the longitudinal mobility of the median nerve only had one sonologist investigating ultrasound images to ensure consistency and reliability. ${ }^{27,28}$ Coppieters et al and Korstanje et al did not report the number of sonologists who investigated the movement of the nerve. ${ }^{13,29}$

Our study found moderate to perfect inter-rater reliability and variable repeatability of the two assessors between the first and second MSUS readings using MTAP. These results suggest that a number of factors that may have influenced the readings of our assessors, including the quality of the MSUS machine, the nerve scan protocol, the computer, and the motion tracker used, did not adversely affect the readings. To ensure reliability of our assessors, a pilot test which used the same MSUS machine promoting uniformity in the procurement of MSUS images, was done. As a result of this test, a strict measurement protocol was implemented.

Specifically, at the wrist, there was a specified location of the feature of interest (FOI) on both wrist and distal upper arm as stated in the Methodology section. The screens of the laptops used by the assessors had different numbers of pixels which could yield inconsistent results. To prevent this error, only one laptop was used in the assessment. Finally, the low contrast and low signal-to-noise ratio in the MSUS images of the median nerve that adds to the difficulty in imaging was improved by grayscale adjustments incorporated in the MTAP. ${ }^{22,23}$ Our results are comparable to Coppieter et al study which demonstrated almost perfect inter-rater reliability of the three assessors who analysed the ultrasound sequences with an ICC of $0.96(95 \% \mathrm{Cl}: 0.883$, 0.988). ${ }^{13}$ The assessors' inter-rater reliability had better results than that of the sonologists. These results are similar to the results of Koppenhaver et al and Teyhen et al which evaluated the inter-examiner and intra-examiner reliability of musculoskeletal ultrasound in measuring the thickness of transversus abdominis and lumbar multifdius. ${ }^{8,30}$ Koppenhaver et al and Teyhen et al concluded that a majority of the measurement error is introduced during image acquisition as opposed to during measurement of muscle thickness on a previously obtained image. 18,30

Our study was able to determine the absolute reliability of MTAP. Absolute reliability is more clinically applicable because it provides the minimum change in measurement that will ensure that the change is greater than measurement error. ${ }^{19}$ Furthermore, SEM and MDC allow clinicians and researchers to quantify the amount of change needed compared with that expected as a result of errors. SEM is a standard deviation and can be used to form a band around a given score. ${ }^{31}$ For the 
median nerve mobility at the distal upper arm, the SEM ranged from 0.02 to $0.03 \mathrm{~mm}$ and the MDC ranged from 0.05 to $0.5 \mathrm{~mm}$. The SEM of the median nerve mobility at the wrist ranged from 0.06 to $0.31 \mathrm{~mm}$ while the MDC ranged from 0.16 to $0.86 \mathrm{~mm}$. We could not compare our results with those of the other studies because the movement of the joints were different in the two studies, which could influence the amount of motion of the nerve. ${ }^{13,14}$ For Hough et al, the movement of the wrist was 60 degrees extension but the shoulder was kept in a slightly flexed position, while our study kept the shoulder in 90 deg flexion. ${ }^{14}$ Median nerve mobility was obtained at the wrist. The study of Coppetiers et al had cervical spine lateral flexion in addition to the flexion/extension of the elbow. ${ }^{13}$ Median nerve mobility was captured at the distal upper arm.

\section{STUDY LIMITATIONS}

This is a study which involved six participants, although there was a total of 36 measurements performed by each of the sonologist for the median nerve excursion on the wrist and distal upper arm. It is recommended that future studies also include repeatability of the sonologists in capturing the mobility of the median nerve.

\section{CONCLUSION}

MTAP using fast template tracking with an adaptive template is a reliable tool that can be employed in the assessment of medial nerve mobility with a good inter-rater reliability of the sonologists and assessors, variable repeatability testing, and modest SEM. Furthermore, its ease of application, fast implementation, and being a stand-alone program on any personal computer are additional features that will make the program a more practical application in investigating therapeutic interventions in improving nerve motion.

\section{REFERENCES}

1. Duckworth A, Jenkins P, Roddam P, Watts A, Ring D, McEachan J. Pain and carpal tunnel syndrome. J Hand Surg. 2013; 38(8):1540-6. [PMID: 23890497]

2. Uchiyama S, Itsubo T, Nakamura K, Kato H, Yasutomi T, Momose T. Current concepts of carpal tunnel syndrome: pathophysiology, treatment, and evaluation. J Orthop Sci. 2010 Jan; 15(1):1-13. doi: 10.1007/s00776-009-1416-x. Epub, 2010 Feb 12. [PMID: 20151245]

3. Gomes I, Becker J, Ehlers JA, Nora D. Prediction of the neurophysiological diagnosis of carpal tunnel syndrome from the demographic and clinical data. Clin Neurophysiol. 2006; 117(5):964-71. [PMID: 16516550]

4. Medina McKeon JM, Yancosek KE. Neural Gliding Techniques for the Treatment of Carpal Tunnel Syndrome: A Systematic Review. J Sport Rehabil. 2008; 17(3):324-41. [PMID: 18708684]

5. Ferry $S$, Hannaford $P$, Warskyj $M$, Lewis $M$, Croft $P$. Carpal tunnel syndrome: a nested case-control study of risk factors in women. Am J Epidemiol. 2000; 151(6):566-74. [PMID: 10733038]

6. Braddom R, Chan L, Harrast M, Kowalske K, Matthews D, et al. Physical Medicine and Rehabilitation, 4e. Philadelphia: Elsevier, 2011.

7. Atroshi I, Gummesson C, Johnsson R, Ornstein E, Ranstam J, Rosen I. Prevalence of carpal tunnel syndrome in a general population. JAMA. 1999 Jul; 282(2):153-8. [PMID: 10411196]

8. Ettema AM, Amadio PC, Zhao C, Wold LE, O'Byrne MM, Moran SL, An KN. Changes in the functional structure of the tenosynovium in idiopathic carpal tunnel syndrome: a scanning electron microscope study. Plast Reconstr Surg. 2006; 118(6):1413-22. [PMID: 17051112]

9. Hirata H, Nagakura T, Tsujii M, Morita A, Fujisawa K, Uchida A. The relationship of VEGF and PGE2 expression to extracellular matrix remodelling of the tenosynovium in the carpal tunnel syndrome. J Pathol. 2004; 204(5):605-12. [PMID: 15538733]

10. Uchiyama S, Itsubo T, Yasutomi T, Nakagawa H, Kamimura M, Kato H. Quantitative MRI of the wrist and nerve conduction studies in patients with idiopathic carpal tunnel syndrome. J Neurol Neurosurg Psychiatry. 2005; 76(8):1103-8. [PMID: 16024888]

11. van Doesburg MH, Henderson J, Mink van der Molen AB, An KN, Amadio PC. Transverse Plane Tendon and Median Nerve Motion in the Carpal Tunnel: Ultrasound Comparison of Carpal Tunnel Syndrome Patients and Healthy Volunteers. PLoS ONE. 2012; 7(5):e37081. doi:10.1371/Journal.Pone.0037081. [PMID: 22606333]

12. Castilho J, Ferreira LA, Pereira WM, Neto HP, Morelli JG, Brandalize D, Kerppers II, Oliveira CS. Analysis of electromyographic activity in spastic bicepsbrachii muscle following neural mobilization. J Bodyw Mov Ther. 2012; 16(3):364-8. [PMID: 22703748]

13. Coppieters M, Hough AD, Dilley A. Different Nerve-Gliding Exercises Induce Different Magnitudes of Median Nerve Longitudinal Excursion: An In Vivo Study Using Dynamic Ultrasound Imaging. J Orthop Sports Phys Ther. 2009; 39(3):16471. [PMID: 19252262]

14. Hough AD, Moore AP, Jones MP. Measuring longitudinal nerve motion using ultrasonography. Man Ther. 2000; 5(3):17380. [PMID: 11034888] 
15. Heebner M, Roddey T. The Effects of Neural Mobilization in Addition to Standard Care in Persons with Carpal Tunnel Syndrome from a Community Hospital. J Hand Ther. 2008; 21(3):229-40. [PMID: 18652967]

16. Hough AD, Moore AP, Jones MP. Measuring longitudinal nerve motion using ultrasonography. Man Ther. 2000; 5(3):17380. [PMID: 11034888]

17. Dilley A, Greening J, Lynn B, Leary R, Morris V. The use of cross-correlation analysis between high-frequency ultrasound images to measure longitudinal median nerve movement. Ultrasound Med. Biol. 2001; 27(9):1211-8. [PMID: 11597362]

18. Koppenhaver SL, Hebert JJ, Fritz JM, Parent EC, Teyhen DS, Magel JS. Reliability of rehabilitative ultrasound imaging of the transversus abdominis and lumbar multifidus muscles. Arch Phys Med Rehabil. 2009; 90(1):87-94. [PMID: 19154834]

19. Donoghue D, Physiotherapy Research and Older People (PROP) group, Stokes E. How much change is true change? The minimum detectable change of the Berg Balance Scale in elderly people. J Rehabil Med. 2009; 41(5):343-6. [PMID: 19363567]

20. Stauffer ME, Taylor SD, Watson DJ, Peloso PM, Morrison A. Definition of Nonresponse to Analgesic Treatment of Arthritic Pain: An Analytical Literature Review of the Smallest Detectable Difference, the Minimal Detectable Change, and the Minimal Clinically Important Difference on the Pain Visual Analog Scale. Int J Inflammation. 2011; 2011:231926. doi: 10.4061/2011/231926. Epub 2011 May 5. [PMID: 21755025]

21. Erel E, Dilley A, Greening J, Morris V, Cohen B, Lynn B. Longitudinal Sliding of the Median Nerve in Patients with Carpal Tunnel Syndrome. J Hand Surg Br. 2003; 28(5): 439-43. [PMID: 12954253]

22. Nicoud F, Castellazzi G, Lesniewski PJ, Thomas JC. Velocity determination of nerve tissue from ultrasound video images. Proc. of the $18^{\text {th }}$ National Congress of the Australian Inst. of Physics, Adelaide, 2008; 73-6. http://www.aip.org.au/info/sites/default/files/Congress2008/AIPC2008/PDF/AUTHOR/AP081363.PDF. ISBN1867346574, Australian Institute of Physics.

23. Nicoud F, Castellazzi G, Lesniewski P, Thomas JC. Fast template tracking in video sequences. Review of Scientific Instruments. 2011;82(10):105110. http://link.aip.org/link/?RSI/82/10/htmltoc doi:10.1063/1.3650711. [PMID: 22047332]

24. Martinoli C, Bianchi S, Pugliese F, Bacigalupo L, Gauglio C, Valle M, Derchi L. Sonography of Entrapment Neuropathies in the Upper Limb (Wrist Excluded). J Clin Ultrasound. 2004; 32(9):438-50. Published online in Wiley InterScience (www.interscience.wiley.com). DOI: 10.1002/jcu.20067. [PMID: 15558622]

25. McLellan DL, Swash M. Longitudinal sliding of the median nerve during movements of the upper limb. J Neurol Neurosurg Psychiatry. 1976; 39(6):566-70. [PMID: 950567]

26. Bilecenoglu B, Uz Z, Karalezli N. Possible anatomic structures causing entrapment neuropathiesof the median nerve: An anatomic study. Acta Orthop Belg. 2005; 71(2):169-76. [PMID: 16152850]

27. Hough AD, Moore AP, Jones MP. Reduced longitudinal excursion of the median nerve in carpal tunnel syndrome. Arch Phys Med Rehabil. 2007;88(5):569-76.[ PMID: 17466724]

28. Erel E, Dilley A, Turner S, Kumar P, Bhatti WA, Lees VC. Sonographic measurements of longitudinal median nerve sliding in patients following nerve repair. Muscle Nerve. 2010; 41(3):350-4. [PMID: 19813195]

29. Korstanje JW, Scheltens-De Boer M, Blok JH, Amadio PC, Hovius SE, Stam HJ, Selles RW. Ultrasonographic assessment of longitudinal median nerve and hand flexor tendon dynamics in carpal tunnel syndrome. Muscle Nerve. 2012; 45(5):721-9. [PMID: 22499100]

30. Teyhen DS, Miltenberger CE, Deiters HM, et al. The use of ultrasound imaging of the abdominal drawing-in maneuver in subjects with low back pain. J Orthop Sports Phys Ther. 2005; 35(6):346-55. [PMID: 16001906]

31. Denegar C, Ball D. Assessing Reliability and Precision of Measurement: An Introduction to Intraclass Correlation and Standard Error of Measurement. J Sport Rehab. 1993; 2:35-42.

32. Gonzalez-Suarez, $\mathrm{C}$ et al. Median Nerve Mobility Measurement Using a Motion Tracking Analysis Program: A Reliability Study. Internet Journal of Allied Health Science and Practice. July 2015, Volume 13 no. 3 